\title{
Stability of isooctane mixtures with 3-pentanone or biacetyl as fluorescence tracers in combustion experiments
}

Received: 6 June 2005/ Revised: 12 August 2005/ Accepted: 8 September 2005/ Published online: 11 October 2005

(C) Springer-Verlag 2005

\begin{abstract}
Evidence is presented in the literature that common fluorescence tracer/fuel mixtures used in engine experiments, 3-pentanone/isooctane and biacetyl/isooctane, may decompose during extended use and storage. Investigations presented here show that preferential evaporation of the tracer and not chemical decomposition is responsible for observed decreases in fluorescence signal strength in these experiments.
\end{abstract}

\section{Introduction}

Tracer-based laser-induced fluorescence (LIF) imaging investigations using mixtures of 3-pentanone or biacetyl in isooctane have found widespread applications in science and engineering (Schulz and Sick 2005). During early use of LIF tracers for internal combustion engine research, observations were reported that the fluorescence signals from 3-pentanone and biacetyl mixed into isooctane decrease over time under otherwise constant conditions. For biacetyl in isooctane, the decrease rate has been measured to be approximately $11 \%$ per hour (Baritaud and Heinze 1992), and the signal decrease from 3-pentanone in isooctane has been determined to be approximately $50 \%$ after $10 \mathrm{~h}$ (Neij et al. 1994). Since there was no change in the physical environment (pressure, temperature) that could give rise to a change in fluorescence quantum yield, chemical decomposition was considered as a potential reason for the observed

R. Zhang $\cdot$ S. V. Bohac $\cdot$ V. Sick $(\varangle)$

Department of Mechanical Engineering,

W. E. Lay Automotive Laboratory,

The University of Michigan, 1231 Beal Avenue,

Ann Arbor, MI 48109-2133, USA

E-mail: vsick@umich.edu

Tel.: + 1-734-6479607

Fax: + 1-734-7644256 signal decay. This assumption has occasionally resurfaced in the literature, but has never been substantiated and is therefore investigated in this paper.

Smith and March (2001) report no evidence that ketones or diones react with isooctane or decompose via unimolecular reactions at temperatures where the tracer/ fuel mixture was stored in the reported experiments $\left(<100^{\circ} \mathrm{C}\right)$. By contrast, Großmann (1994) found that at several hundred degrees Celsius, ketones seem to decompose at increased rates upon contact with stainless steel surfaces. Recently, a series of publications, Le Coz et al. (1994), Lin and Sick (2002), and Davy et al. (2003), addresses the fact that 3-pentanone and isooctane form an azeotropic mixture, and 3-pentanone preferentially evaporates from dilute mixtures with isooctane. The properties of biacetyl are even more dissimilar to those of isooctane, making preferential evaporation even more of a concern. This issue is related to the problem statement above, since it could lead to depletion of the tracer in the mixture if the storage container is open to the atmosphere. Standard fuel systems have pressure relief setups that allow evaporation of fuel. The long-term composition of 3-pentanone/isooctane and biacetyl/isooctane mixtures was therefore studied under different temperature conditions with and without the presence of stainless steel surfaces. Mixture compositions were analyzed through gas chromatography (GC).

\section{Experimental set-up}

Three groups of experiments were performed in this study, each with mixtures of 3-pentanone in isooctane $(15 \% / 85 \%$ by volume) and biacetyl in isooctane $(10 \% /$ $90 \%$ by volume). The composition was chosen as typical for LIF measurements in engines. In the first group, eight $6.5 \mathrm{~mL}$ samples were prepared from each mixture and filled into $8-\mathrm{mL}$ glass vials with snap-on plastic lids in an air atmosphere. The vials were kept in the dark at $20^{\circ} \mathrm{C}$. Each vial was opened at a different time to remove a sample for $\mathrm{GC}$ analysis. In the second group of 
experiments, similar samples were prepared, and a $2-\mathrm{cm}$ length of stainless steel tubing was added to each sample to represent the metal present in engine fuel handling systems. One half of the mixtures were analyzed before and after holding at $20^{\circ} \mathrm{C}$ for $54 \mathrm{~h}$, while the other half of the mixtures were analyzed before and after being kept at $52^{\circ} \mathrm{C}$ for $48 \mathrm{~h}$. In the third group of experiments, samples without stainless steel tubing were prepared and left open to ambient air. Air at $52^{\circ} \mathrm{C}$ was circulated around the glass containers, as the solutions were periodically analyzed as they evaporated.

To measure a mixture composition, $0.1 \mu \mathrm{L}$ of solution was removed from the respective glass container with a stainless steel syringe and transferred to the injection port of a Shimadzu GC-17A. The sample was vaporized at $250^{\circ} \mathrm{C}$, diluted with a $50: 1$ split ratio, pushed through a $2-\mathrm{m}$ deactivated silica pre-column and a $60-\mathrm{m}$ polysiloxane main column maintained at $50^{\circ} \mathrm{C}$, and analyzed with a flame ionization detector. Helium was used as the carrier gas. Both columns had an inner diameter of $0.32 \mathrm{~mm}$ and the main column, a Restek Rtx-1, had a film thickness of $1 \mu \mathrm{m}$.

\section{Results and discussion}

The first group of samples showed a decrease in 3-pentanone concentration of about $5 \%$ in 25 days and a decrease in biacetyl concentration of about $5 \%$ in 16 days. Nine contaminants were detected in each solution at the beginning of the tests, but their combined response only accounted for about $0.25 \%$ of the total. No new hydrocarbons were detected in the mixtures at any time after the start of the investigation, and the amount of each contaminant remained essentially constant. This result demonstrates that mixtures of 3-pentanone/isooctane or biacetyl/isooctane do not decompose at a substantial level at room temperature. It is reasonable to assume that the tracer molecules preferentially evaporated and escaped via the snap-on lids, as is confirmed below.

The second group of samples showed no changes in 3-pentanone/isooctane or biacetyl/isooctane mixture composition while they were kept at $20^{\circ} \mathrm{C}$ for $54 \mathrm{~h}$ in the presence of stainless steel, or while being heated to $52^{\circ} \mathrm{C}$ for $48 \mathrm{~h}$ with the presence of stainless steel. Impurities, whose sum equaled about $0.4 \%$, also did not change. Apparently, the presence of stainless steel or moderate heating in the presence of stainless steel and air does not cause decomposition of the mixtures.

For the third group of samples, the composition of both mixtures changed significantly over the course of the experiment as shown in Figs. 1 and 2. The first data point was taken immediately after each mixture preparation. In $30 \mathrm{~h}$, the concentration of 3-pentanone decreased from 15.00 to $0.48 \%$, and that of biacetyl decreased from 10.00 to $2.43 \%$, and then increased again. The concentration of hydrocarbon impurities in both mixtures changed insignificantly.

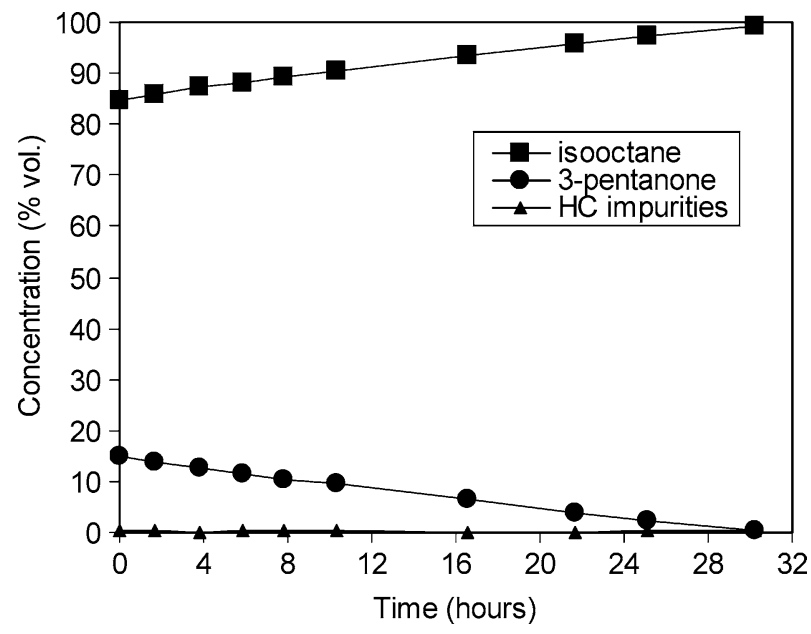

Fig. 1 Composition of 3-pentanone/isooctane solution versus time. Ninety-five percent of the solution was evaporated after $30 \mathrm{~h}$ at $52^{\circ} \mathrm{C}$. Impurity concentrations are below $0.4 \%$ with no significant time dependence

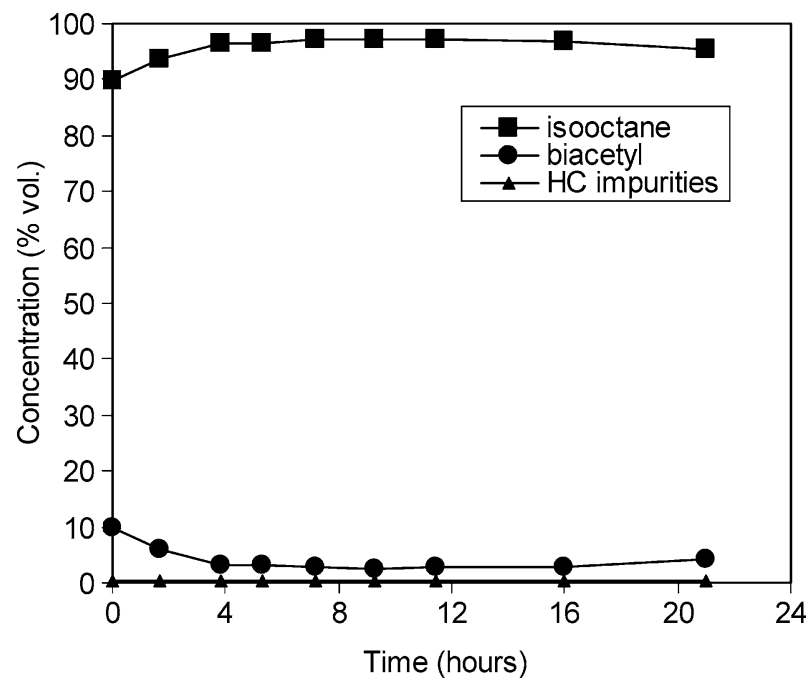

Fig. 2 Composition of biacetyl/isooctane solution versus time Ninety percent of the solution was evaporated after $21 \mathrm{~h}$ at $52^{\circ} \mathrm{C}$. Impurity concentrations are below $0.4 \%$ with no significant time dependence

Typically, mixtures of polar and non-polar liquids show azeotropic behavior. For 3-pentanone/isooctane mixtures, the mole fraction of 3-pentanone in the azeotropic mixture is on the order of 0.4 with some temperature-dependence (Fuchs et al. 1984; Lin and Sick 2002; Davy et al. 2003). The 3-pentanone concentration in our experiments is $15 \%$, which is smaller than that of the azeotropic mixture at the same temperature; therefore, the mixture exhibits preferential evaporation of 3pentanone.

Although no data were found for biacetyl/isooctane in the literature, biacetyl/toluene mixtures show azeotropic behavior (Drye and Prausnitz 1965; Gmehling and Bolts 1996; Joseph et al. 2001), which suggests that 
biacetyl/isooctane azeotropic behavior is likely. This agrees with the observed depletion of biacetyl in the biacetyl/isooctane mixture. After $8 \mathrm{~h}$, the solution became cloudy every time it was briefly cooled to room temperature to remove a sample for analysis; it would become clear again as soon as the mixture was heated to $52^{\circ} \mathrm{C}$. The solution may have polymerized or absorbed water from the air, which caused the cloudiness. One interesting phenomenon also starts at this time: a reversal of the preferential evaporation of biacetyl began, and the concentration of biacetyl now increased with time, indicating that a preferential evaporation of isooctane happened.

\section{Conclusions}

A series of experiments were conducted to investigate the stability of 3-pentanone/isooctane and biacetyl/isooctane mixtures via GC measurements in order to identify the reason of observed fluorescence signal loss over time in some engine experiments. The results show that 3-pentanone/isooctane (15\%/85\% by volume) and biacetyl/isooctane $(10 \% / 90 \%$ by volume $)$ mixtures are chemically stable at test conditions typical for tracer/fuel mixtures in engine experiments. No new species were found, but the mixtures showed obvious preferential evaporation. It is concluded that preferential evaporation, and not chemical decomposition, is the mechanism that causes the observed fluorescence signal decrease.

Acknowledgment This work was supported by General Motors Corporation through the General Motors-University of Michigan Collaborative Research Laboratory on Engine Systems Research.

\section{References}

Baritaud T, Heinze T (1992) Gasoline distribution measurements with PLIF in a SI engine. SAE technical paper 922355

Davy M, Williams P, Han D, Steeper R (2003) Evaporation characteristics of the 3-pentanone/isooctane binary system. Exp Fluids 35:92-99

Drye RV, Prausnitz JM (1965) Thermodynamic properties of some binary solutions containing hydrocarbons and polar organic solvents. Trans Faraday Soc 61:1338-1346

Fuchs R, Krenzer L, Gaube J (1984) Excess properties of binary mixtures composed of a polar component and an alkane. Ber Bunsenges Phys Chem 88:642-649

Gmehling J, Bolts R (1996) Azeotropic data for binary and ternary systems at moderate pressures. J Chem Eng Data 41:202-209

Großmann F (1994) Laserinduzierte Fluoreszenz von 3-Pentanon, Azeton und Azetaldehyd. Diplomarbeit in Physical chemistry, Universität Heidelberg, Heidelberg

Joseph MA, Raal JD, Ramjugernath D (2001) Phase equilibrium properties of binary systems with diacetyl from a computer controlled vapor-liquid equilibrium still. Fluid Phase Equilibr 182:157-176

Le Coz J, Catalano C, Baritaud T (1994) Application of laser induced fluorescence for measuring the thickness of liquid films on transparent wall. In: Seventh international symposium of laser techniques to fluid mechanics, Lisbon, Portugal, 29.3.1-8

Lin M-T, Sick V (2002) Mixture evaporation characteristics prediction for LIF measurements using PSRK (Predictive SoaveRedlich-Kwong) equation of state. SAE Trans J Fuels Lubr 111:1490-1499

Neij H, Johansson B, Alden M (1994) Development and demonstration of 2D-LIF for studies of mixture preparation in SI engines. Combust Flame 99:449-457

Schulz C, Sick V (2005) Tracer-LIF diagnostics: quantitative measurement of fuel concentration, temperature and fuel/air ratio in practical combustion systems. Prog Energy Combust Sci 31:75-121

Smith MB, March J (2001) March's advanced organic chemistry: reactions, mechanisms, and structure, 5th edn. Wiley, New York 